\title{
Anti-Aging Activity of Xylocarpus Granatum Phytoextracts and Xyloccensins K Compound
}

\author{
Syarif Maulana Yusuf ${ }^{1}$, Rika Indri Astuti ${ }^{1,3,}{ }^{*}$, Irmanida Batubara ${ }^{2,3}$, Warinthorn Chavasiri ${ }^{4}$
}

1. Department of Biology, Faculty of Mathematics and Natural Sciences, IPB University, IPB Dramaga Campus, West Java, 16680, Indonesia.

2. Department of Chemistry, Faculty of Mathematics and Natural Sciences, IPB University, IPB Dramaga Campus, West Java, 16680, Indonesia.

3. Tropical Biopharmaca Research Center, IPB University, IPB Taman Kencana Campus, Taman Kencana Street No. 3, Bogor, 16128, Indonesia.

4. Department of Chemistry, Faculty of Sciences, Chulalongkorn University, 254 Phayathai Road, Pathumwan, Bangkok, 10330, Thailand

\begin{tabular}{l}
\hline Info Article \\
\hline Submitted: 09-03-2021 \\
Revised: 18-05-2021 \\
Accepted: 14-09-2021 \\
*Corresponding author \\
Rika Indri Astuti \\
Email: \\
rikaindriastuti@apps.ipb.ac \\
.id
\end{tabular}
.id

\begin{abstract}
Cellular aging is promoted by the deleterious effect of free radicals. This can be lowered by antioxidant treatments. Xylocarpus granatum and its compound, Xyloccensins $\mathrm{K}$ have been reported to have antioxidant activity but there have been no reports of antioxidant and anti-aging activities at the cellular level. Thus, this study aimed to investigate the antioxidant and antiaging properties of X. granatum-derived extract and Xyloccensins $\mathrm{K}$ at a cellular level in yeast Schizosaccharomyces pombe. Four vegetative and three generative parts of X. granatum organs including root, stem, leaf, twig, seed, flesh of the fruit, and peel of the fruit were extracted using $70 \%$ ethanol by the maceration method. Whereas, Xyloccensins $\mathrm{K}$ was obtained from the seed of $X$. granatum. The samples, other than peel of the fruit, were tested for prolonged cell longevity at lower concentrations as compared to that without phytoextracts treatment. Also, our data indicate that all samples could promote oxidative stress tolerance phenotype, as yeasts were capable of dealing with $\mathrm{H}_{2} \mathrm{O}_{2}$-induced oxidative stress treatment at 1,2 , and $3 \mathrm{mM}$ $\mathrm{H}_{2} \mathrm{O}_{2}$ with the best phenotypes by the administration of twig extracts. Most of the phytoextracts showed an increase in mitochondrial activity, except that of seed extract. The result showed the administration of Xyloccensins $\mathrm{K}$ compound did not increase the expression of transcriptional factors of oxidative stress response gene cluster, sty1, and pap1. We suggest that the Xyloccensins K compound acts as a direct Reactive Oxygen Species (ROS) scavenger. Thus, further study in elucidating the phenomenon of $X$. granatum extract-induced longevity is required.
\end{abstract}

Keywords: $X$. granatum Antioxidant, Longevity, Reactive Oxygen Species (ROS)

\section{INTRODUCTION}

Aging is characterized by a loss of physiological integrity that causes malfunction and increased susceptibility to death (Otín et al., 2013). Aging is induced by various factors, including oxidative stress affected by free radicals (Rahal et al., 2014). The cause of oxidative stress is free radical compounds that come from both extrinsic (ex. pesticides and environmental chemicals) and intrinsic (ex. metabolism process) factors. The damaging effect of free radicals can cause the loss of function and structure of healthy cells (Liochev, 2013). However, a cell has an endogenous (enzymatic) antioxidant mechanism to maintaining redox homeostasis in cells. On the other hand, there is also an exogenous (non-enzymatic) antioxidant that can be obtained from nutritional intake (Chodakowska et al., 2018). The antioxidant compounds have been commonly found in plant resources, including mangroves. Indonesia has the highest mangrove diversity in the world with a total of 89 species (Zamani et al., 2015), yet, 
exploration toward antioxidant activity from mangrove plant species is very limited, including $X$. granatum.

Mangrove has unique metabolite compounds caused by environments with high abiotic and biotic stress (Simlai and Roy, 2013). Thus, this is suggesting its potential application in the pharmaceutical field (Das et al., 2019). One of the unique mangrove metabolite compounds is the limonoid, including Xyloccensins K-derived $X$. granatum seed (Kokpol et al., 1996). Based on the previous study, the antioxidant activity of the ethanol extract of $X$. granatum stem, assessed with with the 2,2-diphenyl-1-picrylhydrazyl (DPPH) method, had 50\% inhibition concentration ( $\mathrm{IC}_{50}$ ) value of $23.8 \mu \mathrm{g} \cdot \mathrm{mL}^{-1}$ (Batubara et al., 2010), while that of Xyloccensins I was $0.041 \mu \mathrm{g} \cdot \mathrm{mL}^{-1}$ (Das et al., 2015). The antioxidant activity of $X$. granatum belongs to the very active category (Minami et al., 1998). However, Xyloccensins $K$, another Xyloccensins compound, has not been known to have antioxidant activity.

Furthermore, $S$. pombe as a model organism of eukaryotes is commonly used to understand the mechanism of antioxidant and anti-aging activities in humans (Fontana et al., 2010; Roux et al., 2006). Yeast has several advantages, among others, including having a short lifespan, no complex genome of DNA, some information on some metabolic characters, and molecular genetics that homologous with humans (Palermo et al., 2012; Roux et al., 2006; Xiang et al., 2011). The homology of these cellular pathways includes the activity of the sir2 gene, which regulates cell longevity (Roux et al., 2010), autophagy-a programmed cell death mechanism (Barbosa et al., 2019), and a mitochondria-dependent mechanism that plays a role in oxidative stress responses (Fehrmann et al., 2013). In yeast, mitogen-activated protein kinase (MAPK) Sty1 is essential for the regulation of transcriptional responses that promote cell survival in response to different types of environmental stimuli including oxidative stress conditions which are induced by high peroxide conditions (Berlanga et al., 2010). In response to mild oxidative stress, transcriptional factor, Pap1 mediates the expression of stress response element genes, which overlapped with the Sty1-modulated downstream gene (Veal et al., 2007). In this regard, the activity of Sty1 and Pap1 modulate the expression of antioxidant enzymes (gpx1, ctt1, sod, tpx1, srx1) (Calvo et al., 2012; Zuin et al., 2010), and the other cellular mechanisms in delaying cell aging (rad52, ste11) (Bellini et al., 2012). Both Sty1 and
Pap1 play a key role in oxidative stress response in yeast, these two genes are often used as a marker for understanding the underlying mechanism of oxidative response mechanism in various environmental conditions (Kar et al., 2018; Madrid et al., 2004; Zuin et al., 2010).

To date, there have been no reports available regarding the antioxidant and anti-aging activities from phytoextracts of $X$. granatum and Xyloccensins $\mathrm{K}$ compound at the cellular level. Thus, in this study, we attempted to evaluate the potential of antioxidant and anti-aging activities from phytoextracts of $X$. granatum and Xyloccensins K compound by using $S$. pombe as a model organism. To the best of our knowledge, this is the first study to describe the activity of phytoextracts from X. granatum and Xyloccensins K compound in modulating yeast longevity.

\section{MATERIAL AND METHODS}

\section{Cultures and medium}

The fission yeast S. pombe ARC 039 (h-leu132 ura4-294) (Prastya et al., 2018) S. pombe was routinely maintained in Yeast Extract with Supplement (YES) medium. YES (1 L) composition is as follows: $5 \mathrm{~g}$ yeast extract, $20 \mathrm{~g}$ glucose, $0.128 \mathrm{~g}$ histidine, $0.128 \mathrm{~g}$ leucine, $0.128 \mathrm{~g}$ adenine, $0.128 \mathrm{~g}$ arginine, and 0.010g uracil (Prastya et al., 2018). The yeast was sub-cultured in a liquid YES medium for the stock and working cultures then incubated at room temperature.

\section{Preparation of the samples}

The phytoextracts of $X$. granatum were derived from both vegetative and generative organ parts of the plant including root, stem, seed, the flesh of the fruit, leaf, peel of the fruit, and twig. The phytoextracts were obtained from the previous study (Batubara et al., 2010). All samples were extracted using the maceration method with ethanol as a solvent (Batubara et al., 2010). The Xyloccensins $\mathrm{K}$ compound was derived from the previous study obtained from $X$. granatum seeds (Kokpol et al., 1996). All samples were stocked with $10000 \mu \mathrm{g} . \mathrm{mL}^{-1}$ using distilled water for the extracts and DMSO (dimethylsulfide) for the compound of Xyloccensins K.

\section{Aging assay}

The aging assay was conducted by a spot test as described previously with slight modification. The inoculum was re-inoculated on a $3 \mathrm{~mL}$ YES treatment culture (in a $10 \mathrm{~mL}$ test tube) with an initialOD ${ }_{600}$ of 0.05.Phytoextractsdilutedon 
Table I. Primer pairs for Real-Time PCR used in this study

\begin{tabular}{lll}
\hline Gene & Forward primer & Reverse primer \\
\hline sty1 & 5'-TCACCGTGATCTGAAACCA-3' & 5'-AGCCAAACCGAAATCGCAGA-3' \\
pap1 & 5'-TGGATGGCGATGTTAAGCCT-3' & 5'-GCAGCACGGTTTTGAGCTTT-3' \\
act1 & 5'-CGGTCGTGACTTGACTGACT-3' & 5'-ATTTCACGTTCGGCGGTAGT-3' \\
\hline
\end{tabular}

aquadestwere supplemented in the treatment culture. The assay was performed at three different concentrations $\left(250,500\right.$, and $750 \mu \mathrm{g} \cdot \mathrm{mL}^{-1}$ for the phytoextracts treatment and 25, 50, and $100 \mu \mathrm{g} \cdot \mathrm{mL}^{-1}$ for the Xyloccensins $\mathrm{K}$ compound treatment). Yeast cultured in YES medium containing 3\% glucose without samples was used as the negative control while yeast was cultured in Edinburgh Minimum Medium (EMM) containing $0.5 \%$ of glucose without phytoextracts was used as the positive control. Low glucose in the positive control is considered as calorie restriction (CR) conditions. Such CR condition will induce yeast cellular mechanisms including mitochondrial activity response to oxidative stress and autophagy, which contribute to the yeast lifespan extension (Roux et al., 2010; Sarima et al., 2019). Each culture was incubated for $11^{\text {th }}$-days where a spot test was conducted at days 7 and 11 of incubations. Each culture was adjusted to $\mathrm{OD}=1$ then serially diluted (up to $10^{-4}$ ). About $2 \mu \mathrm{L}$ from each diluted suspension was then spotted on a solid YES medium. The spotted medium was incubated for 3 days at room temperature.

\section{Oxidative stress tolerance assay}

The spot test was carried out as mentioned above but the concentration used is the best concentration during the aging assay. About $2 \mu \mathrm{L}$ from each dilution suspension was spotted on solid YES medium containing $\mathrm{H}_{2} \mathrm{O}_{2}$ at various concentrations $(1,2$, and $3 \mathrm{mM})$.

\section{Active mitochondrial staining}

The procedure was performed according to the previous study by using Rhodamine $\mathrm{B}$ as a probe (Sarima et al., 2019). The yeast was incubated in liquid YES medium supplemented with phytoextracts of $X$. granatum and Xyloccensins $\mathrm{K}$ at the best concentration during the aging assay. The yeast suspension $(1 \mathrm{~mL})$ was centrifuged and the pellet obtained was suspended using phosphate buffer and added with 100nM rhodamine B. Yeast suspensions were then incubated for $30 \mathrm{~min}$ at $25^{\circ} \mathrm{C}$. Light exposure was avoided throughout the experiment. Mitochondrial activity was observed under fluorescence microscopy using 1000x magnification. Strong fluorescence intensity correlates to strong mitochondrial membrane potential (Sarima et al., 2019).

\section{Gene expression assay using quantitative Real- Time Polymerase Chain Reaction (qRT-PCR)}

Yeast was cultured in $3 \mathrm{~mL}$ liquid YES

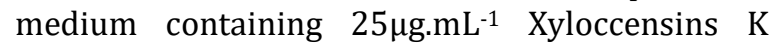
overnight in a shaking incubator. The yeast culture was divided into 2 groups, the oxidative stress conditions (administration of $\mathrm{H}_{2} \mathrm{O}_{2}$ ) and normal conditions. Furthermore, yeast-mRNA was extracted by using the RNeasy Mini Kit (Qiagen, USA). The total of mRNA was used as a template for cDNA synthesis using the iScript cDNA Synthesis Kit (Bio-Rad, USA). The qRT-PCR experiment was performed using the particular cDNA template with Fast Evagreen $\AA$ qPCR Master Mix. PCR mix was prepared following the manufacturer's procedure with specific primers of gene sty1 and pap1 (Table I). The qRT-PCR conditions were predenaturation for $30 \mathrm{~s}$ at $95^{\circ} \mathrm{C}, 50$ amplification cycles (denaturation for $30 \mathrm{~s}$ at $98^{\circ} \mathrm{C}$, annealing for $20 \mathrm{~s}$ at $58^{\circ} \mathrm{C}$, and melting curve for $5 \mathrm{~s}$ at $65^{\circ} \mathrm{C}$ ). Data obtained from qRT-PCR were analyzed using relative quantification method 2- $\Delta \Delta \mathrm{CT}$ and normalized towards reference gene act1 (Livak and Schmittgen, 2001).

\section{RESULT AND DISCUSSION}

In the present study, we report the antiaging properties of phytoextracts derived from vegetative (Figure 1) and generative (Figure 2) organ parts of $X$. granatum, and Xyloccensins K (Figure 3) were able to prolong the lifespan of $S$. pombe. Our findings showed various phenotypic responses upon administration of samples on yeast cell viability. Phytoextracts derived from root, stem, leaf, twig, seed, flesh of the fruit, and Xyloccensins $\mathrm{K}$ which were administrated the lowest concentration (250 $\mu \mathrm{g} \cdot \mathrm{mL}^{-1}$ for phytoextracts and $25 \mu \mathrm{g} . \mathrm{mL}^{-1}$ for Xyloccensins $\mathrm{K}$ ) 
showed as the optimum concentration in prolonging the lifespan of $S$. pombe cells at the stationary phase $\left(7^{\text {th }}\right.$ and $11^{\text {th }}$ days of incubation), compared to that without phytoextracts addition. On the other hand, peel of the $X$. granatum fruit extract showed an anti-aging effect at a higher concentration $\left(500 \mu \mathrm{g} \cdot \mathrm{mL}^{-1}\right)$ (Figure 2).

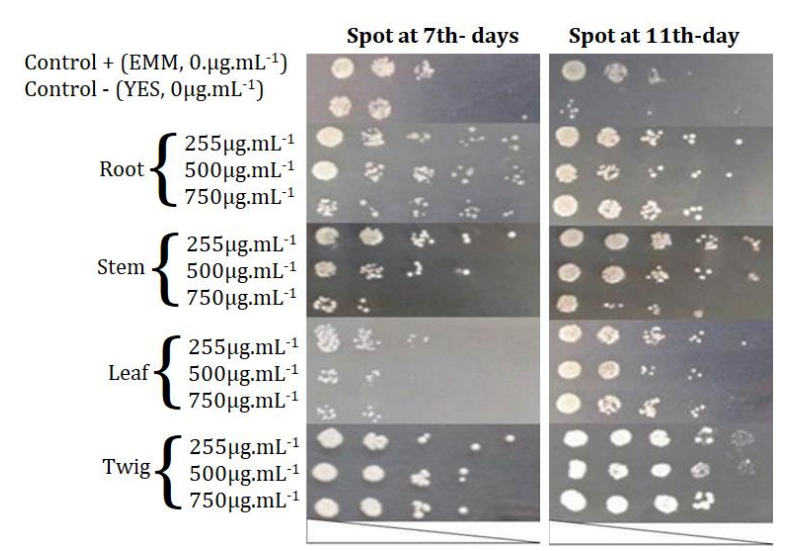

Figure 1. The effect of phytoextracts derived from the vegetative organ parts of $X$. granatum on the viability of $S$. pombe cells. All extract could promote yeast survival rate at the stationary phase ( 7 and 11 days of incubation). Yeast was grown in YES medium supplemented with various concentrations of phytoextracts $(250,500$, and $750 \mu \mathrm{g} . \mathrm{mL}^{-1}$ ) and incubated for 7 and 11 days. Yeast cultures of each designated incubation time were then spotted on YPD agar and incubated for three days prior to observation.

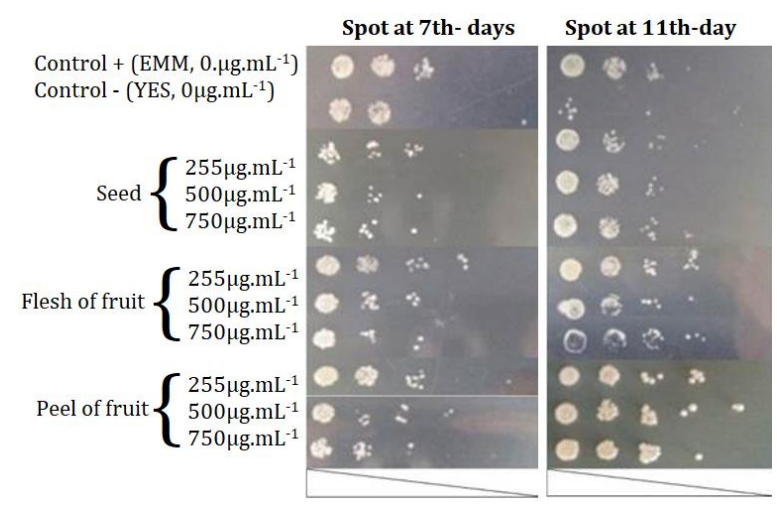

Figure 2. The effect of phytoextracts derived from the generative organ parts of $X$. granatum on the viability of $S$. pombe cells. All extract could promote yeast survival rate at stationary phase (7 and 11 days of incubation) compared to that without extract treatment. Yeast was grown in YES medium supplemented with various concentrations of phytoextracts $\left(250,500\right.$, and $\left.750 \mu \mathrm{g} \cdot \mathrm{mL}^{-1}\right)$ and incubated for 7 and 11 days. Yeast cultures of each designated incubation time were then spotted on YPD agar and incubated for three days prior to observation.

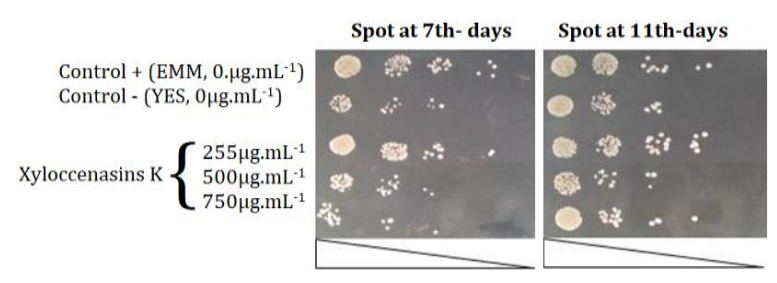

Figure 3. The effect of Xyloccensins $\mathrm{K}$ on the viability of $S$. pombe cells. Yeast was grown in YES medium supplemented with various concentrations of Xylloccensins $\mathrm{K}\left(25,50\right.$, and $\left.100 \mu \mathrm{g} \cdot \mathrm{mL}^{-1}\right)$ and incubated for 7 and 11 days. Yeast cultures of each designated incubation time were then spoted on YPD agar and incubated for three days prior to observation.

Furthermore, the administration of the samples resulted in better cell viability for the 11 days culture, except that of root-derived extract treatment (Figure 1). Assessment of the viability of the cells on days 7 and 11 was based on the previous study as the viability of $S$. pombe cell grown on nutrient-rich medium decrease on the $7^{\text {th }}$ day and almost none survived on the $10^{\text {th }}$ day onwards. ${ }^{[30]}$ It is worth noting, phytoextracts of the root, stem, leaf, twig, flesh of the fruit, and peel of the fruit could promote yeast viability better than that of yeast grown in calorie restriction (CR) conditions (positive control). Whereas, administration of seed extract and Xyloccensins K showed no difference to that of positive control (Figure 3). Interestingly, Xyloccensins K compounds showed better density results $\left(10^{-3}\right)$ compared to $X$. granatum seed extracts $\left(10^{-2}\right)$ (Figures 2 and 3).

CR condition has been known to be able to prolong the lifespan of various organisms including yeast, worms, flies, and mice (Masoro, 2005). In yeast, CR conditions could change the metabolic system from fermentation to respiration that affected various cellular aspects including the activity of mitochondrial and intracellular antioxidants mechanisms, which will ultimately inhibit the cell aging process. Whereas in non-CR conditions, including negative control and treatments, S. pombe was treated in nutrient-rich conditions. Commonly, the amount of nutrient concentration used for the antiaging assay is 
determined by reducing $3 \%$ to $0.5-0.05 \%$ of glucose (Roux et al., 2010). The viability of S. pombe on spot medium is the basis of qualitative determination of antiaging activity.

Previous studies have also reported that some phytoextracts of Hibiscus sabdariffa petal (Sarima et al., 2019), Cimifuga racemosa rhizome, Valeriana officinalis root, Passiflora incarnata, Gingko biloba leaves, Apium graveolens seeds, and Salix alba stems could extend the lifespan of $S$. cerevisiae under conditions that mimic CR conditions with different cellular mechanisms (Lutchman et al., 2016). This is in line with this study, the phytoextracts administration of $X$. granatum (vegetative and generative organ parts) and Xyloccensins $\mathrm{K}$ were able to prolong the lifespan of yeast that mimicking CR conditions, even though yeast was grown in non-CR conditions. Thus, we suspect the phytoextracts of $X$. granatum and Xyloccensins $\mathrm{K}$ might induce anti-aging mechanisms like CR conditions. The spot viability appearance of $S$. pombe yeast on the solid YES medium is the basis for determining the ability of qualitative anti-aging activities. To further clarify the cellular modulation of the phytoextracts and Xyloccensins $\mathrm{K}$ in $S$. pombe, we assessed the capability of extract in promoting intracellular defense against exogenous oxidative stress treatments, mitochondrial activity, and expression of transcriptional factors (sty1 and pap1) for oxidative stress response-related genes in $S$. pombe.

The viability assay against $\mathrm{H}_{2} \mathrm{O}_{2}$-induced oxidative stress could induce oxidative stress tolerance of yeast $S$. pombe with the administration of all phytoextracts derived from both vegetative (Figure 4) and generative organ parts (Figure 5) of $X$. granatum, and also Xyloccensins K (Figure 6) on the $11^{\text {th }}$ day of incubations as compared to the positive control (CR condition). This treatment may likely interfere with yeast cellular function, thus promoting oxidative stress response in yeast.

This is in line with the previous studies using several phytoextracts in modulating the oxidative stress tolerance phenotype of different yeast isolates. For instance, phytoextracts of Syzygium aromaticum leaves and Coffea sp. seed (caffeine compound) could increase the longevity of $S$. pombe (Fauzya et al., 2019; Maeta et al., 2007). In addition, phytoextracts of Hibiscus sabdariffa and quercetin could promote the longevity of $S$. cerevisiae (Belinha et al., 2007; Sarima et al., 2019). Interestingly, the administration of catechin derived from Camellia sinensis leaves could also induce oxidative stress tolerance on both S. pombe and S. cerevisiae cells (Rallis et al., 2013). Besides, the administration of Bacillus SAB E-41 crude extract could also promote modulate oxidative stress tolerance phenotype of $S$. pombe cells (Prastya et al., 2018).

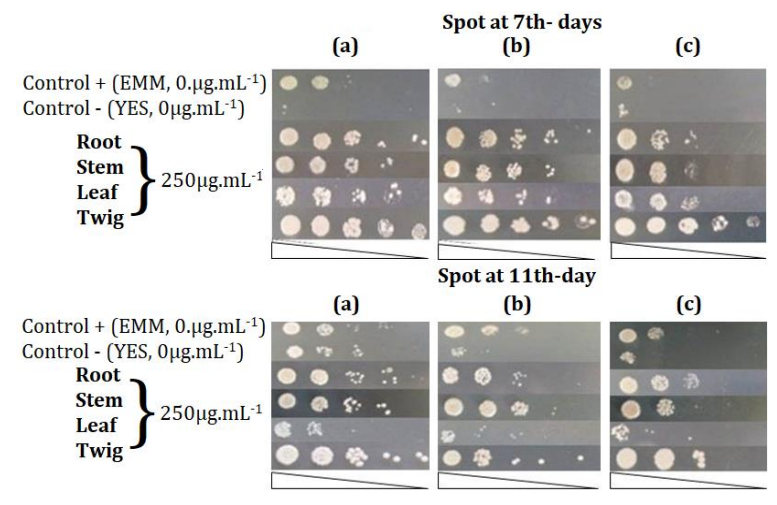

Figure 4. Effect of phytoextracts derived from the vegetative organ parts of $X$. granatum on the viability of S.pombe cells against oxidative stress. All extract could promote yeast survival rate against oxidative stress conditions at the stationary phase (7 and 11 days of incubation). Yeast was grown in YES medium supplemented with selected concentrations of extracts and incubated for 7 and 11 days. Yeast cultures of each designated incubation time were thenspottedd on YPD agar supplemented with various concentrations of oxidative stress using $\mathrm{H}_{2} \mathrm{O}_{2}$ ((a) $1 \mathrm{mM}$, (b) $2 \mathrm{mM}$, (c) $3 \mathrm{mM}$ ) and incubated for three days prior observation.

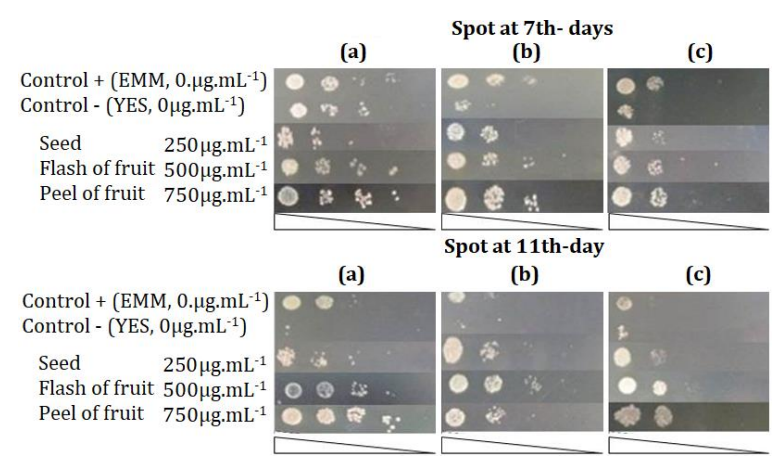

Figure 5. Effect of phytoextracts derived from the generative organ parts of $X$. granatum on the viability of S.pombe cells against oxidative stress. All extract could promote yeast survival rate against oxidative stress conditions at the stationary phase (7 and 11 days of incubation). Yeast was grown in YES medium supplemented with selected concentrations of extracts and incubated for 7 and 
11 days. Yeast cultures of each designated incubation time were then spotted on YPD agar supplemented with various concentrations of oxidative stress using $\mathrm{H}_{2} \mathrm{O}_{2}$ ((a) $1 \mathrm{mM}$, (b) $2 \mathrm{mM}$, (c) $3 \mathrm{mM}$ ) and incubated for three days prior to observation.

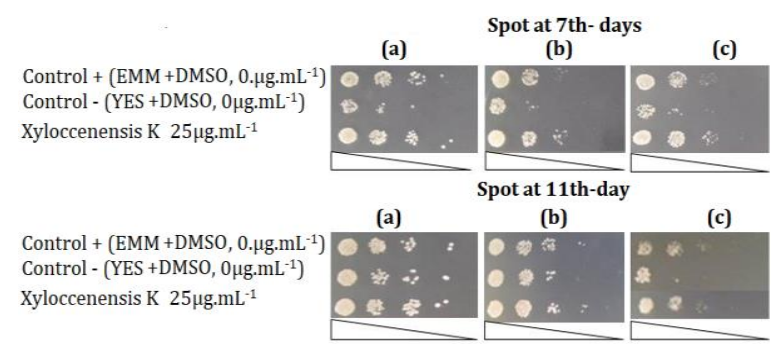

Figure 6. Effect of Xyloccensins K on the viability of S.pombe cells against oxidative stress. Xyloccensins $\mathrm{K}$ could promote yeast survival rate against oxidative stress. Yeast cultures of each designated incubation time were then spotted on YPD agar supplemented with various concentrations of oxidative stress using $\mathrm{H}_{2} \mathrm{O}_{2}$ ((a) $1 \mathrm{mM}$, (b) $2 \mathrm{mM}$, (c) $3 \mathrm{mM}$ ) and incubated for three days prior to observation.

Our data showed that the administration of $250 \mu \mathrm{g} . \mathrm{mL}^{-1}$ of twig-derived extract of $X$. granatum significantly increased cell viability against a high concentration of $\mathrm{H}_{2} \mathrm{O}_{2}(3 \mathrm{mM})$ on day 11 (Figure 4). Such activities have also been reported from the treatment of $100 \mu \mathrm{g} . \mathrm{mL}^{-1}$ of $S$. aromaticum clove extract on S. cerevisiae (Fauzya et al., 2019). On the other hand, a higher concentration of Bacillus SAB E-41 extract was needed to promote yeast viability against low $0.75 \mathrm{mM} \mathrm{H}_{2} \mathrm{O}_{2}$ (Prastya et al., 2018).

Up to this date, this study is the first report to show the potential properties of phytoextracts from vegetative (root, stem, leaf, and twig) and generative (seed, flesh of fruit, and peel of fruit) organ parts of $X$ granatum and Xyloccensins $\mathrm{K}$ as an antioxidant at the cellular level. In the previous study at the acellular level, the phytoextracts compounds that play a role as antioxidants are limonoids. In the DPPH, ABTS, superoxide, and hydrogen peroxide assays, the limonoid such as Xyloccensins I was known to have IC 50 at 0.041 , $0.039,0.096$, and $0.235 \mathrm{mg} / \mathrm{mL}$, respectively (Das et al., 2019). Xyloccensins are limonoid group compounds found only in the Rutaceae and Meliaceae families (Bandaranayake, 2002; Cui et al., 2008). Limonoid structures are classified into phragmaline, mexiconalide, obacunol, and andyrobin types based on their carbon rings (Wu et al., 2015; Zhou et al., 2014). Limonoids are highly oxygenated, have moderate polarity, insoluble in water and hexane, but are soluble in hydrocarbons, alcohols, and ketones (Roy \& Saraf, 2006).

The induction of intracellular oxidative stress response has been reported to be related to the mitochondrial activity (Sarima et al., 2019). This is supported by the theory of mitochondrias as ROS-producing organelles (Barzilai et al., 2012) and mitochondrial dysfunction as a signal of aging. Furthermore, phytoextracts of $X$. granatum (vegetative and generative organ parts) and Xyloccensins $\mathrm{K}$ were analyzed towards mitochondrial activities.

Based on our observation, all the phytoextracts of vegetative organ parts could promote mitochondrial membrane activity (Figure 7), compared to the control. In addition, most of the phytoextract of generative organ parts, except seed extract, could also promote mitochondrial membrane activity (Figure 8), compared to the control. Interestingly, the administration of Xyloccensins K (Figure 9) had a different effect to the seed extracts of $X$. granatum (Figure 8). Such difference was likely due to the presence of compounds in crude extracts of seed that act antagonistically in increasing mitochondrial activity. Thus, we suggest that the anti-aging activity of seed extract was unlikely to occur via mitochondrial signaling as likely mediated via Xyloccensins K.

The mitochondrial activity assay aimed to clarify the possible in vivo induction of yeast mitochondrial activity after the administration of phytoextracts. Thus, it was likely that phytoextract of $X$. granatum and Xyloccensins K may mediate the intracellular oxidative stress response of yeast $S$. pombe via the induction of mitochondrial activity. However, further, the study must be conducted to clarify this phytoextract-mode of action. This was similar to a previous study that suggests plant extracts of $H$. sabdariffa petal promote the cellular response of $S$. cerevisiae against oxidative stress (Sarima et al., 2019). Besides that, other studies revealed a mitochondria-independent action of the ethanol extracts clove leaves and buds in mediating oxidative stress tolerance phenotype of yeast $S$. pombe and S. cerevisiae (Astuti et al., 2019; Fauzya et al., 2019).

Mitochondria are known to be associated with aging because these organelles produce intracellular ROS via respiration. 

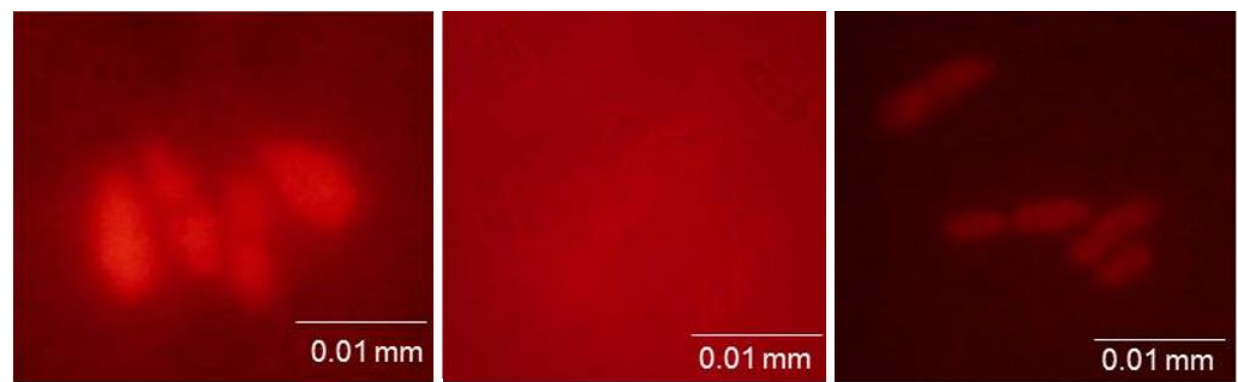

a $\mathrm{b}$ c
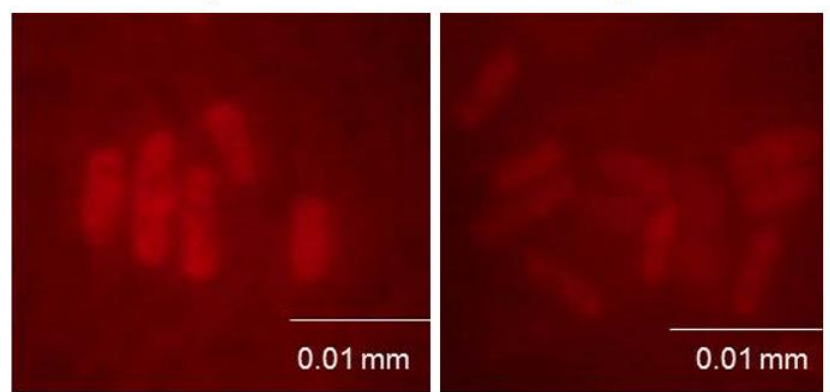

d

e

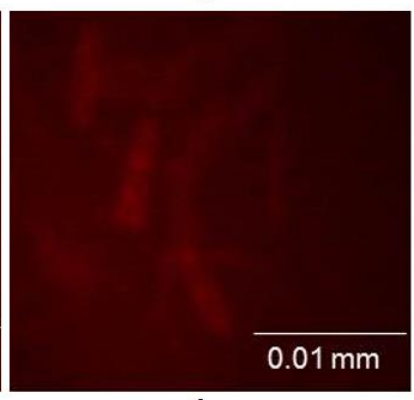

d

Figure 7. Effect of phytoexracts derived from the vegetative organ parts of X. granatum on mitochondrial activity of yeast S. pombe: (a) EMM $0.5 \%$ of glucose (control +, $0 \mu \mathrm{g} \cdot \mathrm{mL}^{-1}$ ), (b) YES 3\% of glucose (control -, $0 \mu \mathrm{g} \cdot \mathrm{mL}^{-1}$ ), (c) YES $3 \%$ of glucose $+250 \mu \mathrm{g} \cdot \mathrm{mL}^{-1}$ of root phytoextract, (d) YES $3 \%$ glucose $+250 \mu \mathrm{g} \cdot \mathrm{mL}^{-1}$ of stem phytoextract, (e) YES 3\% glucose $+250 \mu \mathrm{g} \cdot \mathrm{mL}^{-1}$ of leaf phytoextract, and (f) YES 3\% glucose +250 $\mu \mathrm{g} . \mathrm{mL}^{-1}$ of twig phytoextract. Bar in each picture represents $10 \mu \mathrm{m}$ scale.

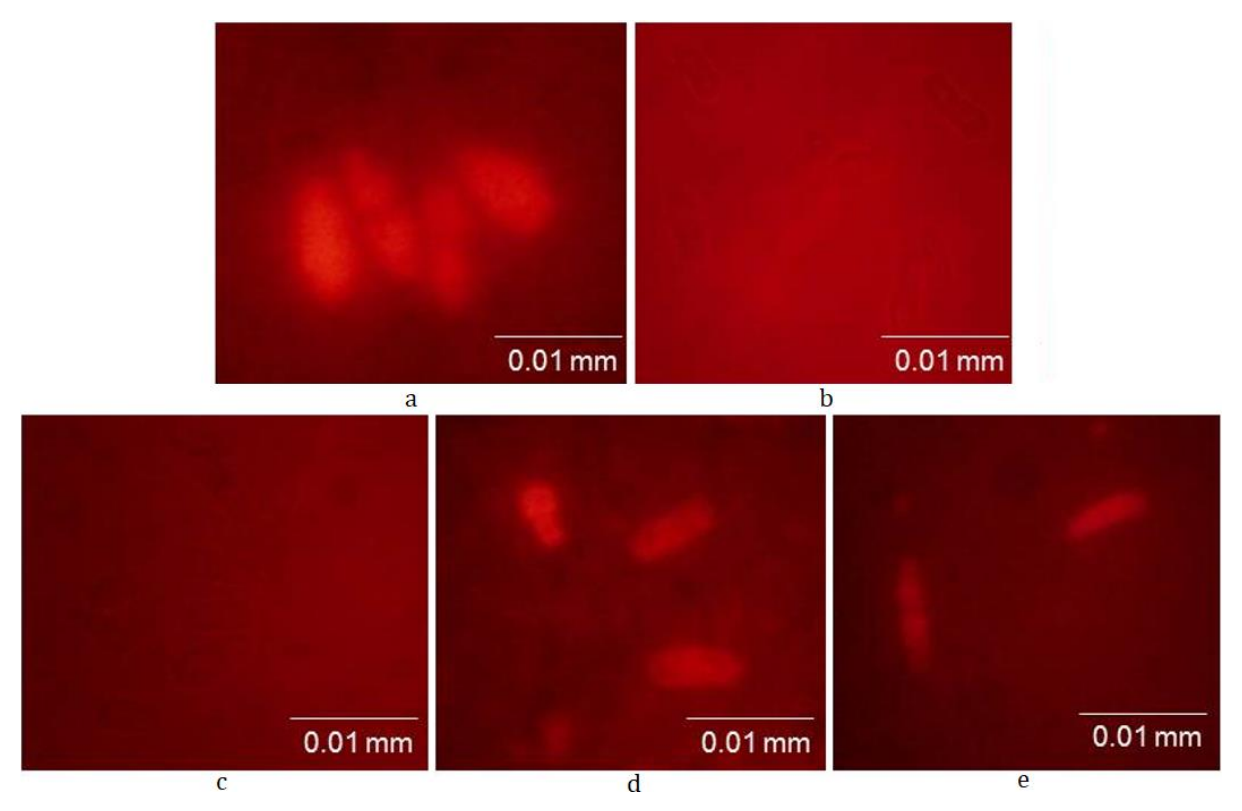

Figure 8. Effect of phytoexracts derived from the generative organ parts of X. granatum on mitochondrial activity of yeast S. pombe: (a) EMM $0.5 \%$ of glucose (control +, $0 \mu \mathrm{g} \cdot \mathrm{mL}^{-1}$ ), (b) YES 3\% of glucose (control -, $0 \mu \mathrm{g} \cdot \mathrm{mL}^{-1}$ ), (c) YES 3\% of glucose $+250 \mu \mathrm{g} \cdot \mathrm{mL}^{-1}$ of seed phytoextract, (d) YES 3\% glucose $+250 \mu \mathrm{g} \cdot \mathrm{mL}^{-1}$ of flesh of fruit phytoextract, and (e) YES $3 \%$ glucose $+500 \mu \mathrm{g} \cdot \mathrm{mL}^{-1}$ of peel of fruit phytoextract. Bar in each picture represents $10 \mu \mathrm{m}$ scale. 

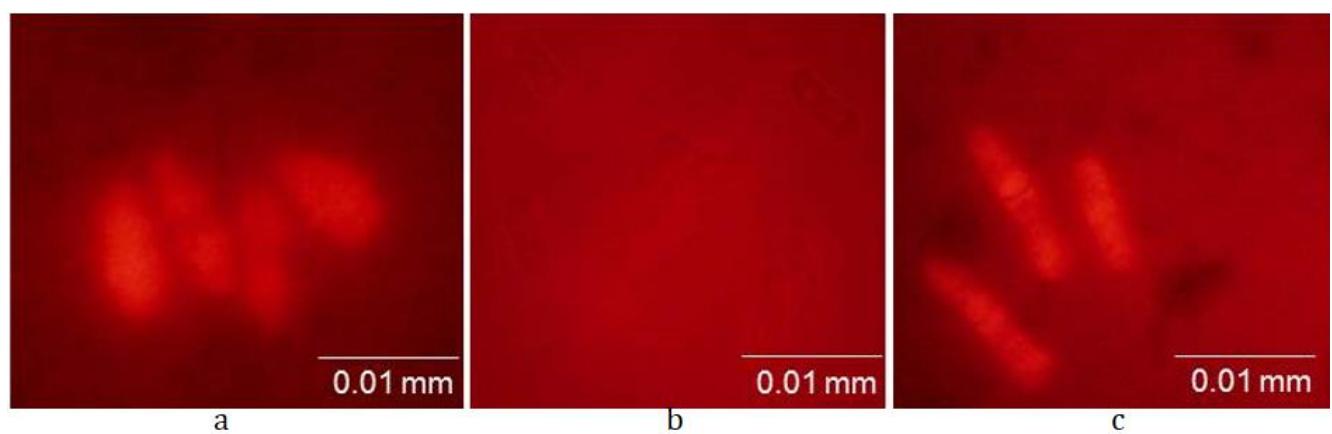

Figure 9. Effect of Xyloccensins K on mitochondrial activity of yeast $S$. pombe: (a) EMM $0.5 \%$ of glucose (control,$+ 0 \mu \mathrm{g} \cdot \mathrm{mL}^{-1}$ ), (b) YES $3 \%$ of glucose (control -, $0 \mu \mathrm{g} \cdot \mathrm{mL}^{-1}$ ), (c) YES 3\% of glucose $+25 \mu \mathrm{g} \cdot \mathrm{mL}^{-1}$ of Xyloccensins K. Bar in each picture represents $10 \mu \mathrm{m}$ scale.

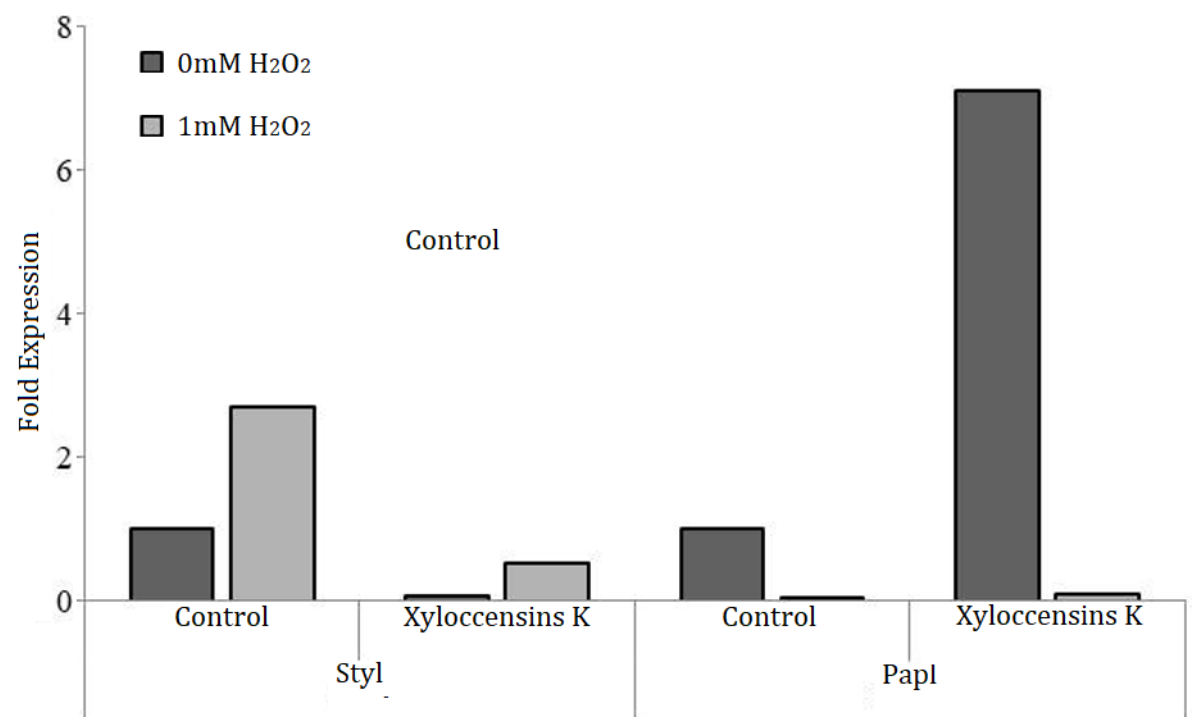

Figure 10. The effects of $25 \mu \mathrm{g}, \mathrm{mL}^{-1}$ Xyloccensins $\mathrm{K}\left(25 \mu \mathrm{g} \cdot \mathrm{mL}^{-1}\right)$ on the gene expression level os transcriptional factor sty1 and pap1-investigated by using qRT-PCR analysis. Yeast re-cultured in YES medium without Xyloccensins $\mathrm{K}$ addition was used as control. The level of gene expression sty1 and pap1 were normalized using reference gene act1.

Thus, mitochondrial dysfunctions could be one of the fundamental causes of cellular aging (Barzilai et al., 2012). Interestingly, the administration phytoextracts of $X$. granatum (vegetative and generative organs), except seed extracts and Xyloccensins $\mathrm{K}$ showed strong fluorescence intensity relatively similar level to that of $\mathrm{CR}$ conditions. The $\mathrm{CR}$ condition is known to be responsible for the development of adaptive mitochondrial ROS-signaling that prolong yeast chronological life span (Pan et al., 2012). Indeed, treatment of those phytoextract and Xyloccensins $\mathrm{K}$ could prolong yeast life span as revealed in this study. Further study is required to understand the effect of phytoextract and Xyloccensins $\mathrm{K}$ at molecular levels. It is worth noting that the development of adaptive mitochondrial-ROS signaling occurs via the reduction of TOR activity (Barzilai et al., 2012).

Amongst all treatments, we specifically analyzed the effect of Xyloccensins K in modulating transcriptional factors of oxidative stress response gene cluster, sty1, and pap1. The expression of both sty1 and pap1 genes was increased following the oxidative stress conditions, suggesting the development of intracellular oxidative stress 
conditions in the S. pombe cells. Such results were in agreement with the previous study as reported elsewhere (Calvo et al., 2012; Vivancos et al., 2004). Indeed, both sty1-atf1 and pap1 pathways are reported as redox sensors that are directly activated by elevated $\mathrm{H}_{2} \mathrm{O}_{2}$ levels (Vivancos et al., 2004). Interestingly, it is shown that there was no increase in the expression of sty 1 and pap1 genes following administration of $25 \mu \mathrm{g} \cdot \mathrm{mL}^{-1}$ Xyloccensins $\mathrm{K}$, compared to the control treatment (Figure 10), thus suggesting that $\mathrm{H}_{2} \mathrm{O}_{2}$-induced oxidative stress conditions did not develop in Xyloccensins K-treated cells.

We suspect that the antioxidant mechanism of Xyloccensins $\mathrm{K}$ was mediated via a direct ROS scavenging mechanism. This was supported by the high activity of Xyloccensins in the in vitro assay (Das et al., 2015). Xyloccensins $\mathrm{K}$ is suspected to rapidly reduce free radicals $\left(\mathrm{H}_{2} \mathrm{O}_{2}\right)$ before affecting the stress oxidative responses genes cluster in $S$. pombe. The Xyloccensins compound is a compound derived from a modified terpenoid group that is highly oxygenated with the general framework 4,4,8-trimethyl-17furanilsteroid (Roy \& Saraf, 2006). Thus, both functions as antioxidant agents. This is supported by the high activity of the Xyloccensins compound group in a previous in-vitro assay (Das et al., 2015). Xyloccensins group of compounds is thought to be able to quickly reduce free radicals $\left(\mathrm{H}_{2} \mathrm{O}_{2}\right)$ such that intracellular oxidative stress conditions are not formed. Such phenomenon has previously been reported as the administration of Curcumin can directly reduce ROS, including $\mathrm{O}_{2}^{-}, \mathrm{OH}^{-}$and $\mathrm{H}_{2} \mathrm{O}_{2}$ on skeletal muscle rats by penetrating cell membranes and transferring $\mathrm{H}$ atoms to free radical compounds in the cytoplasm (Barzegar \& Movahedi, 2011). It is worth noting that, Xyloccensins $\mathrm{K}$ belongs to mexaconalide group which has a unique functional group structure that features easily oxidized properties (Wu et al., 2004). Thus, the Xyloccensins $\mathrm{K}$ may exert an excellent antioxidant agent via direct ROS scavenging activity both in vitro and cellular levels (Das et al., 2015).

\section{CONCLUSION}

Phytoextracts of both vegetative and generative organs of $X$. granatum, and Xyloccensins $\mathrm{K}$ could prolong the lifespan of $S$. pombe cells at different concentrations. Most of the samples showed anti-aging activities at the lowest concentrations $\left(250 \mu \mathrm{g} \cdot \mathrm{mL}^{-1}\right.$ for phytoextracts of root, stem, leaf, twig, seed, and flesh of fruit; 25 $\mu$ g.mL ${ }^{-1}$ for Xyloccensins K), except that of the peel of X. granatum fruit. Twig-derived extract (250 $\mu \mathrm{g} . \mathrm{mL}^{-1}$ ) induced the antioxidative stress phenotype on yeast. Most of the samples could induce mitochondrial activity, except that of the seed extract. It is worth noting that the anti-aging activity of $X$. granatum extract is not all mitochondria-dependent. Furthermore, Xyloccensins $\mathrm{K}$ likely induces a cellular antioxidative mechanism independent of that from Sty1 and Pap1 genes, thus suggesting another mechanism such as direct ROS scavenging activity. Further research is necessary to clarify the underlying mechanism of Xyloccensins $\mathrm{K}$ as an antiaging agent.

\section{ACKNOWLEDGEMENT}

The authors thank the Ministry of Research, Technology, and Higher Education of the Republic of Indonesia for funding through Hibah Dana Penelitian Magister scheme in 2019.

\section{REFERENCES}

Bandaranayake, W. M. (2002). Bioactivities, bioactive compounds and chemical constituents of mangrove plants. Wetlands Ecology and Management, 10(6), 421-452. https://doi.org/10.1023/A:1021397624349

Barbosa, M. C., Grosso, R. A., \& Fader, C. M. (2019). Hallmarks of aging: An autophagic perspective. Hallmarks of Aging and Autophagy, $\quad 9(790), \quad$ 1-13. https://doi.org/10.3389/fendo.2018.00790

Batubara, I., Darusman, L., Mitsunaga, T., Rahminiwati, M., \& Djauhari, E. (2010). Potency of Indonesian medicinal plants as tyrosinase inhibitor and antioxidant agent. Journal of Biological Sciences, 10(2), 138-144. https://doi.org/10.3923/jbs.2010.138.144

Belinha, I., Amorim, M. A., Rodrigues, P., De Freitas, V., Ferreira, P. M., Mateus, N., \& Costa, V. (2007). Quercetin Increases Oxidative Stress Resistance and Longevity in Saccharomyces cerevisiae. J. Agric Food Chem, 55(6), 24462451.

Bellini, A., Girard, P. M., Lambert, S., Tessier, L., Sage, E., \& Francesconi, S. (2012). Stress Activated Protein Kinase Pathway Modulates Homologous Recombination in Fission Yeast. PLOS ONE, 7(10), 1-12. https://doi.org/10.1371/journal.pone.0047 987

Berlanga, J. J., Rivero, D., Martín, R., Herrero, S., Moreno, S., \& de Haro, C. (2010). Role of 
mitogen-activated protein kinase Sty1 in regulation of eukaryotic initiation factor $2 \alpha$ kinases in response to environmental stress in Schizosaccharomyces pombe. Eukaryotic Cell, 9(1), 194-207. https://doi.org/10.1128/EC.00185-09

Calvo, I. A., García, P., Ayté, J., \& Hidalgo, E. (2012). The transcription factors Pap1 and Prr1 collaborate to activate antioxidant, but not drug tolerance, genes in response to H 202. Nucleic Acids Research, 40(11), 4816-4824. https://doi.org/10.1093/nar/gks141

Chodakowska, I. M., Witkowska, A. M., \& Zujko, M. E. (2018). Endogenous non-enzymatic antioxidants in the human body. Advances in Medical Sciences, 63(1), 68-78. https://doi.org/10.1016/j.advms.2017.05.0 05

Cui, J., Ouyang, J., Deng, Z., \& Lin, W. (2008). Structure elucidation of an unprecedented alkaloid and a new limonoid from Xylocarpus granatum. Magnetic Resonance in Chemistry, 46(9), https://doi.org/10.1002/mrc.2273

Das, S. K., Samantaray, D., Sahoo, S. K., Pradhan, S. K., Samanta, L., \& Thatoi, H. (2019). Bioactivity guided isolation of antidiabetic and antioxidant compound from Xylocarpus granatum J. Koenig bark. 3 Biotech, 9(5), 1-9. https://doi.org/10.1007/s13205-019-1711$\mathrm{y}$

Das, S. K., Samantaray, D., \& Thatoi, H. (2015). Ethnomedicinal, Antimicrobial and Antidiarrhoeal Studies on the Mangrove Plants of the Genus Xylocarpus: A Mini Review. Journal of Bioanalysis \& Biomedicine, 12(4), 1-7. https://doi.org/10.4172/1948593x.s12-004

Fauzya, A. F., Astuti, R. I., \& Mubarik, N. R. (2019). Effect of Ethanol-Derived Clove Leaf Extract on the Oxidative Stress Response in Yeast Schizosaccharomyces pombe. International Journal of Microbiology, 2019, 1-7. https://doi.org/10.1155/2019/2145378

Fehrmann, S., Paoletti, C., Goulev, Y., Ungureanu, A., Aguilaniu, H., \& Charvin, G. (2013). Article Aging Yeast Cells Undergo a Sharp Entry into Senescence Unrelated to the Loss of Mitochondrial Membrane Potential. Cell Reports, 5(6), 1589-1599. https://doi.org/10.1016/j.celrep.2013.11.01 3

Fontana, L., Partridge, L., \& Longo, V. D. (2010). Dietary Restriction, Growth Factors and
Aging: from yeast to humans. Science, 328(5976), 321-326. https://doi.org/10.1126/science.1172539.D ietary

Kar, P., Biswas, P., Patra, S. K., \& Ghosh, S. (2018). Transcription factors Atf1 and Sty1 promote stress tolerance under nitrosative stress in Schizosaccharomyces pombe. Microbiological Research, 206(2018), 82-90. https://doi.org/10.1016/j.micres.2017.10.0 02

Kokpol, U., Chavasiri, W., Tip-pyang, S., Veerachato, G., Zhao, F., Simpson, J., \& Weavers, R. T. (1996). A limonoid from Xylocarpus granatum. Phytochemistry, 41(3), 903-905. https://doi.org/10.1016/00319422(95)00724-5

Liochev, S. I. (2013). Reactive oxygen species and the free radical theory of aging. Free Radical Biology and Medicine, 60, 1-4. https://doi.org/10.1016/j.freeradbiomed.20 13.02.011

Livak, K. J., \& Schmittgen, T. D. (2001). Analysis of Relative Gene Expression Data Using RealTime Quantitative PCR and the 2- $\Delta \Delta$ CT Method. Methods, 25(4), 402-408. https://doi.org/10.1006/meth.2001.1262

Lutchman, V., Medkour, Y., Samson, E., Arliaciommo, A., Dakik, P., Cortes, B., Feldman, R., \& Mohtashami, S. (2016). Discovery of plant extracts that greatly delay yeast chronological aging and have different effects on longevity-defining cellular processes. Oncotarget, 7(13), 16542-16566.

Madrid, M., Soto, T., Franco, A., Paredes, V., Vicente, J., Hidalgo, E., Gacto, M., \& Cansado, J. (2004). A cooperative role for Atf1 and Pap1 in the detoxification of the oxidative stress induced by glucose deprivation in Schizosaccharomyces pombe. Journal of Biological Chemistry, 279(40), 41594-41602. https://doi.org/10.1074/jbc.M405509200

Maeta, K., Nomura, W., Takatsume, Y., Izawa, S., \& Inoue, Y. (2007). Green Tea Polyphenols Function as Prooxidants To Activate Oxidative-Stress-Responsive Transcription Factors in Yeasts ?. Applied and Environmental Microbiology, 73(2), 572-580. https://doi.org/10.1128/AEM.01963-06

Masoro, E. J. (2005). Overview of caloric restriction and ageing. Mechanisms of Ageing and Development, 126(2005), 913-922. https://doi.org/10.1016/j.mad.2005.03.012

Minami, H., Hamaguchi, K., Kubo, M., \& Fukuyama, 
Y. (1998). A Benzophenone and a Xanthone from Garcinia subelliptica. Phytochemistry, 49(6), 1783-1785.

https://doi.org/10.1016/s00319422(98)00213-1

Otín, C. L., Blasco, M. A., Partridge, L., Serrano, M., \& Kroemer, G. (2013). The Hallmarks of Aging. Cell, 153(6), 1194-1217. https://doi.org/10.1016/j.cell.2013.05.039

Palermo, V., Mattivi, F., Silvestri, R., La Regina, G., Falcone, C., \& Mazzoni, C. (2012). Apple can act as anti-aging on yeast cells. Oxidative Medicine and Cellular Longevity, 2012(4), 1-8. https://doi.org/10.1155/2012/491759

Prastya, M. E., Astuti, R. I., Batubara, I., \& Wahyudi, A. T. (2018). Bacillus sp. SAB E-41-derived extract shows antiaging properties via ctt1mediated oxidative stress tolerance response in yeast Schizosaccharomyces pombe. Asian Pacific Journal of Tropical Biomedicine, 8(11), 533-539. https://doi.org/10.4103/22211691.245958

Rahal, A., Kumar, A., Singh, V., Yadav, B., Tiwari, R., Chakraborty, S., \& Dhama, K. (2014). Oxidative stress, prooxidants, and antioxidants: The interplay. BioMed Research International, 2014, 1-19. https://doi.org/10.1155/2014/761264

Rallis, C., Codlin, S., \& Bähler, J. (2013). TORC1 signaling inhibition by rapamycin and caffeine affect lifespan, global gene expression, and cell proliferation of fission yeast. Aging Cell, 12(4), 563-573. https://doi.org/10.1111/acel.12080

Roux, A. E., Chartrand, P., Ferbeyre, G., \& Rokeach, L. A. (2010). Fission yeast and other yeasts as emergent models to unravel cellular aging in eukaryotes. Journals of Gerontology - Series A Biological Sciences and Medical Sciences, 65(1), 1-8. https://doi.org/10.1093/gerona/glp152

Roux, A. E., Quissac, A., Chartrand, P., Ferbeyre, G., \& Rokeach, L. A. (2006). Regulation of chronological aging in Schizosaccharomyces pombe by the protein kinases Pka1 and Sck2. Aging Cell, 5(4), 345-357. https://doi.org/10.1111/j.14749726.2006.00225.x

Roy, A., \& Saraf, S. (2006). Limonoids : Overview of Significant Bioactive Triterpenes. Biol. Pharm. Bull., 29(February), 191-201.

Sarima, Astuti, R. I., \& Meryandini, A. (2019). Modulation of Aging in Yeast Saccharomyces cerevisiae by Roselle Petal Modulation of Aging in Yeast Saccharomyces cerevisiae by Roselle Petal Extract (Hibiscus sabdariffa L.). American Journal of Biochemistry and Biotechnology, 15(1), 23-32. https://doi.org/10.3844/ajbbsp.2019.23.32

Simlai, A., \& Roy, A. (2013). Biological activities and chemical constituents of some mangrove species from Sundarban estuary: An overview. Pharmacognosy Reviews, 7(14), 170-178. https://doi.org/10.4103/09737847.120518

Veal, E. A., Day, A. M., \& Morgan, B. A. (2007). Hydrogen Peroxide Sensing and Signaling. Molecular Cell, 26(1), 1-14. https://doi.org/10.1016/j.molcel.2007.03.0 16

Wu, Y. B., Liu, D., Liu, P. Y., Yang, X. M., Liao, M., Lu, N. N., Sauriol, F., Gu, Y. C., Shi, Q. W., Kiyota, H., \& Dong, M. (2015). New limonoids from the seeds of Xylocarpus granatum. Helvetica Chimica Acta, 98(5), 691-698. https://doi.org/10.1002/hlca.201400290

Xiang, L., Sun, K., Lu, J., Weng, Y., Taoka, A., Sakagami, Y., \& Qi, J. (2011). Anti-aging effects of phloridzin, an apple polyphenol, on yeast via the SOD and Sir2 genes. Bioscience, Biotechnology and Biochemistry, 75(5), 854858. https://doi.org/10.1271/bbb.100774

Zamani, N., Gazali, M., \& Batubara, I. (2015). The Study of Tyrosinase and Antioxidant Activity of Xylocarpus Granatum Koenig Seed Kernel Extract toward Evidence Based Indigenous Knowledge from Togean Archipelago, Indonesia. Journal of Marine Science: Research \& Development, 5(3), 1-5. https://doi.org/10.4172/21559910.1000168

Zhou, Z. F., Liu, H. L., Zhang, W., Kurtán, T., Mándi, A., Bényei, A., Li, J., Taglialatela-Scafati, O., \& Guo, Y. W. (2014). Bioactive rearranged limonoids from the Chinese mangrove Xylocarpus granatum Koenig. Tetrahedron, 70(37), 6444-6449. https://doi.org/10.1016/j.tet.2014.07.027

Zuin, A., Carmona, M., Morales-Ivorra, I., Gabrielli, N., Vivancos, A. P., Ayté, J., \& Hidalgo, E. (2010). Lifespan extension by calorie restriction relies on the Sty1 MAP kinase stress pathway. EMBO Journal, 29(5), 981991.

https://doi.org/10.1038/emboj.2009.407 